type, identification details and a summary of the medical details of every casualty dealt with. This, of course, is essential for subsequent dealing with enquiries about pensions, insurance etc., as well as enquiries from relatives.

\title{
Summary
}

It is suggested that under the circumstances of mass casualties a closely adhered-to scheme of medical examination should be followed to make the best use of available medical man power. Such a scheme is described and suggestions made for the best use of ancillary lay persons to support the medical officers. It is considered that such an examination scheme should be used in conjunction with a handling system such as that evolved in the Millhand exercises.

\section{A FIRST AID AND TRANSPORT BURNS DRESSING}

\author{
J. KOHN, M.C.Path, D.C.P. \\ Queen Mary's Hospital, Roehampton, London.
}

A SATISFACTORY transport dressing for major burns should be simple and rapid in application, light in weight, porous so as to permit evaporation, non-adherent, should offer some degree of protection against trauma and infection during transport, cause minimal discomfort to the patient and last, but not least, should be reasonably economical.

These requirement are to a great extent fulfilled by a dressing which I suggested and reported upon in $1963^{1}$ and which I proposed to call the Roehampton Burns Dressing (RBD). Since then further field as well as clinical trials have been carried out and certain modifications introduced. It very soon became apparent that there was no need for a supporting mesh and that the polyurethane foam on its own was strong enough. I have also changed the type of fasteners for fixing the dressing.

In its present form the dressing consists of a sheet of polyurethane foam $\frac{1}{2}$ " thick and of varying size. These sheets can be cut to any size or shape to meet individual requirements and protect any particular part of the body affected. The dressing is packed in a suitable plastic bag and can be sterilised either by autoclaving or gamma irradiation. In a compressed, rolled up form the dressing occupies very little space, a medium size one is only 12 " long and weighs apprixomately 7 ozs.*

Sterilisation by gamma irradiation proved to be eminently successful: Bacteriological sterility tests, performed on a number of dressings after variable periods of storage, both for vegetative forms and spores were, without exception, perfectly satisfactory. The impregnation of the polyurethane foam with a suitable antiseptic has been under consideration and experiments in this direction have been started. This procedure might, provided a suitable antiseptic is found, prevent or delay bacterial contamination and possibly assist in minimising the bacterial colonisation of the burned surfaces. The incorporation of an antiseptic however presents a very tricky problem and should not

*The Dressing is now manufactured and marketed under the name of the "Roehampton Burns, Dressing " by Messrs. Price Brothers \& Company, Ltd.; of Wellington, Somerset. 
be undertaken too hastily without very careful consideration.

Provided the dressing is not left for too long there is very little adherence to the burned surface and this can be further minimised, if considered necessary, by spraying the foam with a suitable silicone preparation.

Various types of devices have been tried for the fastening of the dressing and keeping it in position, e.g. tapes, hooklets, etc. It was eventually found that a type of letter fastener with two pointed blades of unequal length and a large head or washer, was a very simple and practical solution. Such fasteners are commercially available, cheap and can easily be sterilised together with the polyurethane foam. Alternatively, large safety pins or even suitable adhesive tape can be used for fixing the dressing.

As the dressing is porous and permeable it permits evaporation, and consequently assists the drying of the exudate, thus forming part of the eventual exposure treatment, In the nine years since the polyurethane foam was recommended by Evans $(1957)^{2}$ and used by him in the treatment of burns as part of the exposure method, no toxic effects were observed, neither was there any evidence of allergic reactions to the material.

\section{Dressing procedure}

With extensive burns involving most of the body surface, the patient (after removal of clothes and preliminary cleaning of the affected areas, if feasible and where adequate facilities are ayailable) is placed on the dressing (one or two sheets of polyurethane foam depending on the size available) which is then rolled around so as to form a complete envelope or 'cocoon'. For smaller areas, e.g. chest or limbs the polyurethane foam sheet is cut accordingly, wrapped and fastened around the affected part. The inner surfaces

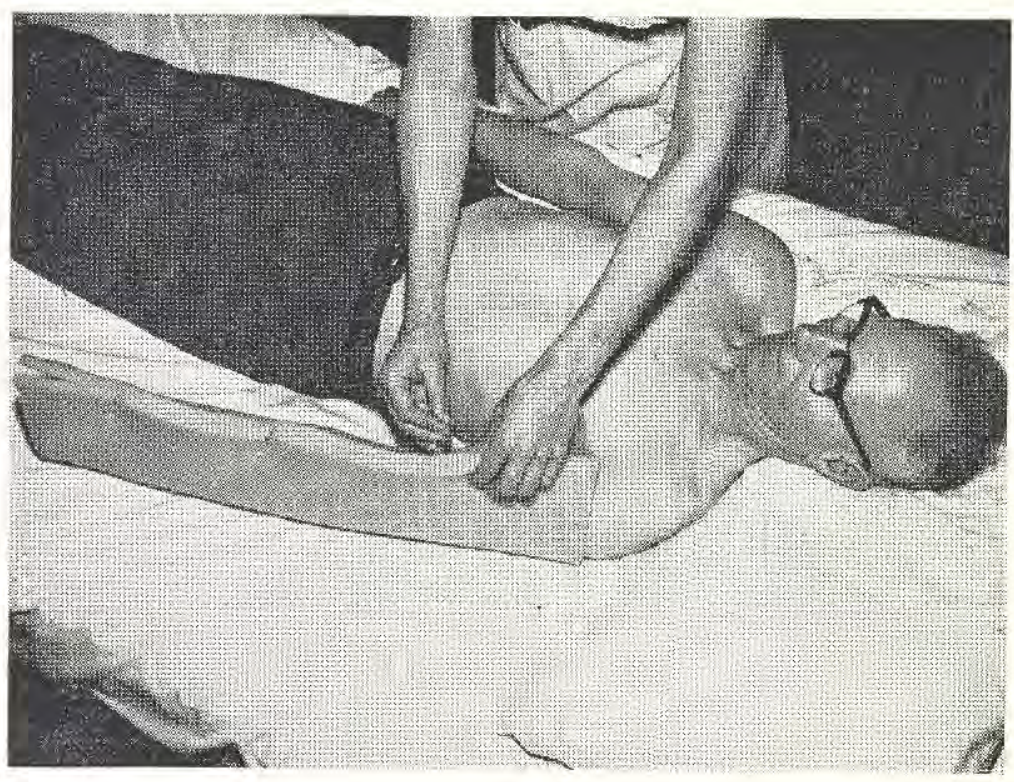

Figure 1

Burns of Arm. The inner surfaces of the edges are opposed to each other before inserting the fasteners, 
of the edges of the polyurethane foam are now opposed to each other and then fixed in position by pushing the fasteners through the material and bending the blades outwards (Figure 1). The whole procedure is very rapid and can be performed by untrained personnel; the application of the dressing over a whole body burn can be carried out in under a minute. The fasteners are applied in such a manner that the dressing follows the contour of the body or limb without being too tight (Figure 2).

It must be emphasised that no other form of dressing should be applied under the foam.

If a transfusion is required a horizontal slit is cut in the material in such a position that a site suitable for vene-puncture is exposed (e.g. the unaffected arm is brought out through the slit and the transfusion given in the cubital vein), (Figure 3). In order to prevent tearing of the polyurethane foam a piece of adhesive tape should be placed over the site where the slit is to be cut.

On arrival at the final destination the fasteners are removed and the dressing simply unfolded. This can be accomplished in a matter of seconds, saving the patient a great deal of pain and in consequence avoiding the necessity of having to administer large doses of drugs or even general anaesthetics. This procedure compares very favourably

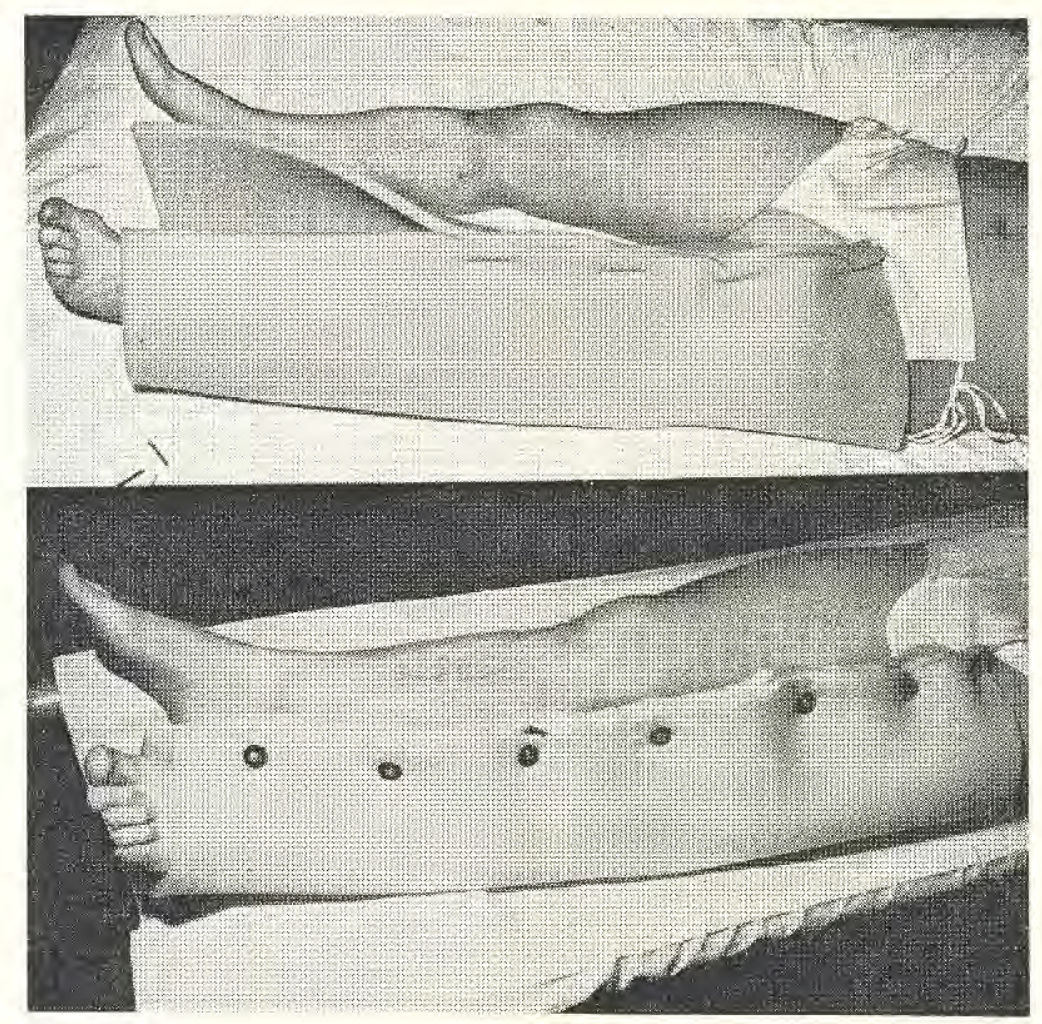

Figure 2

Burns of leg. (a) The RBD applied with four fasteners in position; two more fasteners to be inserted.

(b) The dressing with all fasteners in position, 


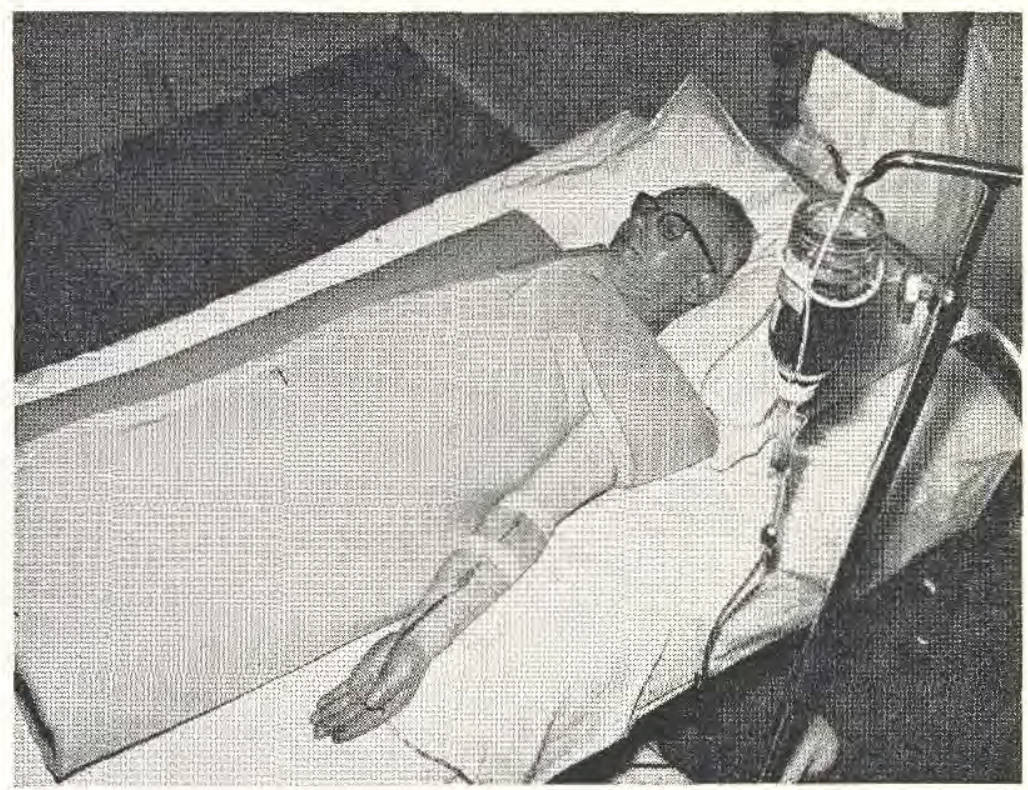

Figure 3

Body burn with the dressing applied, the arm brought through a slit and transfusion in progress. Note adhesive reinforcing the edges of the slit.

with that in which muslin type dressings are applied. The patient can be spared a great deal of unnecessary suffering.

It should be emphasised that in the proposed form the dressing is primarily designed for first aid and transport and not for treatment. The dressing is not meant to stay on for longer than 24 hours. If circumstances (e.g. delay in transport to hospital) necessitate the dressing remaining in position for more than 24 hours, it should be replaced by a new one.

In order to assess the effect of the Roehampton Burns Dressing on the burnt areas, some experiments were carried out by Mr. A. J. Evans in his Burns Unit on patients with symmetrical burns affecting both lower limbs. ${ }^{3}$ A Roehampton Burns Dressing was applied to one limb whereas the other was left exposed. Inspection at 4 hourly intervals up to a period of 24 hours did not reveal any significant difference in the appearance of the burnt surfaces which were only slightly more moist than on the totally exposed limb. There was no difference in the sensation of pain compared with the exposed limb. Following removal of the dressing (after 24 hours) the appearance of the burnt areas on both limbs was closely watched. Swabs for bacteriological investigations were taken from both limbs from the first day. No pathogens were isolated in the first 48 hours.

Further observations were made on cases who were admitted to hospital after having had the Roehampton Burns Dressing applied as a first-aid measure. ${ }^{4}$ There was no evidence of any toxic or allergic manifestations and no unusual features in the subsequent clinical course.

It might be worth mentioning at this stage that the emergency ambulances in the London area carry the Roehampton Burns Dressing on an extended trial basis. So 
far the reports and comments from the casualty personnel as well as from the ambulance crews seem to be very favourable.

\section{The Advantages of Polyurethane Foam Dressing}

(a) The dressing procedure is extremely rapid; this is a most important factor.

(b) It can easily be performed by unskilled personnel

(c) It can be considered as an initial stage of the eventual exposure treatment

(d) It affords a considerable degree of protection against trauma during transport

(e) The removal of the dressing is simple, rapid and virtually painless

(f) It can be sterilised by either heat or gamma irradiation

(g) Packing and storage do not present major difficulties; in fact it may prove to be simpler to pack and store than any other type of dressing

(h) It is adaptable and easy to modify to individual requirements

(i) It is very convenient for casualty transport purposes, as it is much easier to deal with a neat 'package'. For mass casualties and military purposes the dressing has obvious advantages for logistical reasons.

\section{REFERENCES}

1. KoHN, J. (1963) J. roy. Army med. Cps. 109, 4.

2. Evans, A. J. (1957) Brit. Med. J., 1, 547.

3. Evans, A. J. (1966) Trans. 2nd International Congress on research in Burns, Edinburgh 1965, E, \& S. Livingstone Ltd, p.291.

4. Matheson, J. M. (1966), ibid. p.303.

\section{Appointment}

The Queen has approved the appointment and promotion of Brigadier A. MacLennan, O.B.E., M.B., to be Deputy Director of Medical Services with the rank of Major General in succession to the late Major General D. M, Ahern.

Born at Aberdeen on 15th February, 1912, educated at Aberdeen Grammar School and Aberdeen University where he graduated M.B., Ch.B. in 1934. Alastair MacLennan was commissioned in the Corps in 1934 and served in the United Kingdom, Malta North West Europe, India, Korea, Far East, Middle East and B.A.O.R. His senior appointments have included Assistant Director General, The War Office, D.D.M.S. H.Q. B.A.O.R., Inspector of Army Medical Services and D.D.M.S. H.Q.1. (British) Corps.

Appointed O.B.E. in 1945, Officer of the Order of St. John in 1966 he was mentioned in despatches in Korea 1952: He is married with three children. 